\title{
O MUNDO ENGARRAFADO E A ARQUEOLOGIA DA ENCENAÇÃO: GRAVAÇÕES AUDIOVISUAIS COMO REGISTRO DE PRODUCÇÕES OPERÍSTICAS ${ }^{1}$
}

\author{
Mateus Yuri Passos
}

\begin{abstract}
Resumo
Este trabalho se debruça sobre o uso de gravações audiovisuais como documentos para análise de producções de ópera contemporâneas agrupadas pela crítica alemã sob o termo teatro de director [Regietheater]. Nesse conjunto de abordagens, o projeto de obra de arte integral [Gesamtkunstwerk] de Wagner ganha um novo impulso e significado, pois as três dimensões da arte operística - verbal, musical e visual - deixam de trabalhar em conjunto para a mobilização do drama e passam a constituir textos distintos. Neste artigo, discutiremos as limitações da gravação audiovisual para o registro de encenações operísticas de teatro de diretor, assim como recursos de linguagem de montagem fílmica que permitem reconstruir em texto audiovisual essas producções, com soluções por vezes distintas daquelas adotadas em palco. Interessa-nos, sobretudo, problematizar a equivalência que por vezes se estabelece entre uma encenação e sua gravação - especialmente no contexto contemporâneo de produções que realizam alterações frequentes e se caracterizam pelo caráter único de cada performance individual, sempre repleta de eventos singulares, com relativa autonomia em relação ao plano geral de direção. Para isso, discutiremos problemas e soluções da direção de vídeo em gravações audiovisuais de encenações de Der Ring des Nibelungen [O Anel do Nibelungo], de Richard Wagner (1813-1883).
\end{abstract}

\section{Palavras-chave}

Encenação de ópera; gravação de ópera; Regietheater; Richard Wagner; teatro de diretor

\begin{abstract}
This work focuses on the use of the audiovisual opera recording as a document to analyze contemporary stagings labeled by the German critics as director's theater [Regietheater]. In director's theater, Wagner's total artwork project [Gesamtkunstwerk] achieves a turn in meaning, for the three artistic dimensions of opera - word, music and staging - become different texts. In this paper, we discuss the limitations of audiovisual recording as a register of director's theater opera stagings, as well as filmic resources that allow for a reconstruction of the audiovisual text of such productions with solutions that are often quite distinct from those adopted on the stage. We are interested above all in problematizing the equivalence that is sometimes established between a staging and its recording - especially in the contemporary context of productions that frequently suffer considerable changes and are characterized by the unique aspect of each performance, always full of singular events and relatively autonomous regarding the general plan of the director. Thus, we will discuss problems and solutions of video direction of audiovisual recordings of stagings of the operatic cycle Der Ring des Nibelungen [The Ring of Nibelungo], by Richard Wagner (1813-1883).
\end{abstract}

\section{Keywords}

Opera recording; director's theater; opera staging; Regietheater; Richard Wagner

\footnotetext{
' Para uma visão mais aprofundada sobre o assunto, ver tese de doutoramento do autor. Disponível em http://repositorio. unicamp.br/handle/REPOSIP/269953
} 


\section{INTRODUÇÃO: TEATRO DE DIRETOR E OS LIMITES DAS GRAVAÇÕES}

Na sala da cabana de Hunding, sentado à mesa, Wehwalt está angustiado; desprovido de armas, ao amanhecer deverá travar uma luta até à morte com seu anfitrião hoje, assassinou vários membros do clã de Hunding, que forçavam uma mulher a casar contra a sua vontade. O pai de Wehwalt, Wälse, havia lhe prometido uma espada, forte e afiada, que surgiria em um momento de apuro - mas não há sinal dela. Entra em desespero, e vê o reluzir do metal cravado no tronco de um freixo. Chega a esposa de Hunding, que the relata sua vida difícil, e os dois se descobrem mutuamente apaixonados. Resolvem fugir, e para garantir sua segurança precisarão de Notung, a espada que um velho andarilho caolho fincara na árvore, a qual apenas quem fosse digno poderia retirá-la dali. Após a mulher - que, logo descobrirá, é sua irmã gêmea Sieglinde - rebatizá-lo com o nome primordial, Siegmund dirige-se impetuoso para o tronco...

Sobre o que se segue, há fortes divergências: Siegmund pode estar numa rústica cabana medieval, numa mansão burguesa dos anos 1840, 1940 ou 2000, num espaço com poucos móveis, assético, quase laboratorial, num campo florido ou na escura e desolada Via da História. De acordo com a maioria das versões, conquista por suas próprias forças e mérito a espada; noutras, é Sieglinde quem retira a espada do tronco, ou Wotan - real identidade de seu pai, Wälse, e também do andarilho -, invisível a seus olhos, que lhe entrega Notung em mãos; a espada pode até mesmo surgir como num parto, retirada do ventre de Sieglinde.

A cena descrita, que conclui o primeiro ato da ópera Die Walküre [A Valquíria], de Richard Wagner, é uma amostra da variação na caracterização espaço-temporal e no desenrolar das ações que tem sido exercitado nas produções operísticas desde a década de 1960, quando - em meio a uma turbulência de auto-questionamento das práticas e valores da humanidade, como o boom dos movimentos ambientalistas e pacifistas e o feminismo de segunda onda, assim como o despontar de uma "cultura do eu", cada vez mais intensa, simultânea a uma fragilização da noção de identidade na pós-modernidade (Maffesoli, 2011) - surge na República Democrática Alemã [RDA] o paradigma de encenação operística hoje chamado de teatro de director [Regietheater], no qual há deslocamentos em relação ao libretto e à dramaturgia musical e o director torna-se um criador de relativa autonomia.

Hoje, especialmente na Alemanha, cada vez mais as produções de ópera que procuram seguir a ambientação e ação conforme determinadas no libretto cedem lugar àquelas em que a direção se torna um espectáculo em si, que por vezes concorre com a música e o libretto na disputa pela atenção do público, e por vezes se integra e dialoga com eles: evidenciou-se como um terceiro texto, uma terceira dimensão de significados formada por todas as dimensões do aspeto visual, a superfície de contato do público com os personagens e o drama, e recodificada de modo a repensar e mesmo reestruturar a obra a partir de um tratamento autoral da encenação que produz uma leitura singular, imbuída de novos significados. Desde os anos 1980 (Ely, 1984) essa prática recebe da crítica alemã a denominação Regietheater [teatro de direção, ou de director] - houve nomes alternativos, como avancierte Regie [direção avançada] (Garaventa, 2006), ou 
Musiktheater [teatro de música] (Eckert, 1995), que aponta para a coexistência da música e do teatro enquanto focos de realização artística, mas vou preferir aqui o primeiro termo, que põe em destaque o papel do diretor enquanto realizador autoral da encenação e o protagonismo do texto cênico que cria.

As condições de funcionamento do teatro de diretor, desde suas origens na RDA, envolvem uma redefinição de papéis dos encenadores - e portanto também do autor -, dos intérpretes e da crítica. É preciso entender, em primeiro lugar, que o libretto e a partitura compõem juntos apenas uma obra potencial, ideal, e que a ópera somente se constitui como arte completa quando concretizada nos palcos. A primeira postura de encenação - que só passou a ser vista como uma possibilidade dentre outras quando as alternativas surgiram e começaram a muito custo a crescer em importância - procurava observar o texto verbal do libretto, que determinava a ambientação e as ações exteriores, e o texto musical da partitura, de caráter multidimensional - a caracterização interior de personagens e situações, desvelamento de seus sentimentos interiores, e especialmente a partir de Wagner a articulação de comentários externos a eles - e traduzi-los em imagem, transportar o público para o tempo e espaço daquela trama e, de um modo geral, ceder lugar à apreciação da música; ou seja, nessa perspectiva o texto visual - composto por todos os elementos da cena, estáticos ou móveis - pretende ser um meio transparente, que não chama atenção para si mesmo enquanto enunciado.

No teatro de diretor, a equipe criativa de encenação encabeçada pelo diretor cênico, aliado ao cenógrafo e ao figurinista, se coloca numa posição de maior autonomia: o artista realizador abandona uma posição servil em relação aos autores dos textos potenciais - compositor e libretista -, inicialmente como uma postura política, mas também por compreender como limitadora a conceção da atividade do diretor como tradução, renegociando - ou mesmo abolindo - a hierarquia entre os textos potenciais, verbal e musical, e a sua concretização visual. Se na situação primordial de encenação o diretor se sujeitava aos autores, surgem duas novas possibilidades - o diretor dialoga com o autor ou, mais recentemente, se sobrepõe ao autor, coloca-se em confronto com ele nas quais torna-se evidente que o diretor passa também a ser um autor, construindo um texto cênico que interage com os demais.

Um dos marcos na consolidação crítica do teatro de diretor é de natureza linguística: a criação do termo Illusiontheater [teatro de ilusão] nos anos 1960 pelo director Joachim Herz (1989), no intuito de caracterizar e diferenciar as produções "tradicionais" da estética "formalista" de Wieland Wagner e da sua própria estratégia de encenação. A denominação certamente tem caráter pejorativo, remetendo à dimensão escapista e alineada da encenação que se pretende neutra, mas sua adoção faz com que se deixe de enxergá-la como estilo padrão e a coloca como mais uma dentre diversas possibilidades de concretização cênica da ópera - algo análogo à criação do termo heterossexual em contraste a homossexual, ou cisgênero em contraste a transgênero, para que não se veja mais essas formas de orientação sexual e identidade de gênero como desviantes, mas possibilidades dignas de respeito e igualdade.

Além disso, o estabelecimento do conceito de teatro de ilusão nos ajuda a definir, por oposição, o que em termos gerais é o teatro de diretor: enquanto o primeiro pretende 
ser transparente em relação à ópera potencial, em especial à caracterização visual e às ações previstas pelo libretto, o segundo trabalha com diversos graus de opacidade que tornam os significantes originais menos visíveis e os substitui por novos elementos. Porém, da mesma forma como "ópera" é um termo genérico que abarca diversos gêneros de teatro musical com estruturas composicionais bastante distintas - melodramma, opera seria, opera buffa, singspiel, ópera-comique, grand-ópera, Musikdrama, Bühnenfestspiel, Literaturoper, Zeitoper, para-opera, etc. - o conjunto de possibilidades de estratégias de encenação no teatro de diretor é bastante vasto: há diversos gêneros de encenação, ou subcorrentes que operam de modo consideravelmente distinto (Parker \& Abbatte, 2012).

As estratégias de encenação de diversos diretores que se envolveram com produção operística a partir dos anos 1980 - como Robert Wilson, Frank Castorf, Ruth Berghaus, Michael Schulz, Anthony Pilavachi, Guy Cassiers e Carlus Padrissa -, se constroem a partir da tradição de teatro de aspeto principalmente performático denominada por Hans-Thies Lehmann (1999) de teatro pós-dramático, cuja oposição ao teatro político - paradoxalmente, justamente como proposição política - se dá pela negação da lógica causal, da mimese naturalista, do teatro vinculado à formulação literária, estruturado sobre a realização de uma narrativa: considera-o autoritário e ilusionista pelo esforço em replicar no palco uma visão positivista que já não funcionaria no mundo contemporâneo, além de tomar como pressuposto a equivalência entre uma obra (potencial) com a sua performance.

Na perspetiva pós-dramática, o texto é apenas um ponto de partida para a elaboração de uma performance, o acontecimento toma prevalência sobre a estruturação de uma narrativa: a construção de tensão e sua resolução, por exemplo, são aniquiladas de pathos e de continuidade. A própria conceção da performance pós-dramática é pensada como foco na realização em si, em seus aspetos plásticos, em vez da comunicação de ideias, e em sentido mais amplo pela negação de que existe um texto a comunicar.

Com frequência o espectador sofre uma "overdose semiótica": há um excesso de estímulos no palco - não raro, muitas ações simultâneas em que não há diferença hierárquica clara entre elas - excesso de elementos de significação atirados na direção do público sem um princípio organizador evidente. Em ópera, a experiência de assistir a algumas dessas produções não difere muito da leitura do Finnegans Wake de James Joyce (2000): é preciso suspender a necessidade de compreensão imediata - talvez a versão pós-moderna para a noção de "suspensão da descrença" -, deixar-se banhar pela chuva de símbolos - e depois tentar recolher dela alguns fios de compreensão. A própria construção de significado de uma cena, nessa perceção, seria realizada pela plateia - ou seja, cada espectador criaria o significado, ao assistir a uma apresentação.

Tamanho grau de complexidade do trabalho desses diretores, em termos de linguagem simbólica, exige do crítico e do pesquisador de encenação uma apreciação minuciosa dos recursos e estratégias cênicas utilizadas. O uso da gravação audiovisual é, assim, um importante documento da produção, não apenas para fruição, mas também para sua reconstituição por gerações futuras - possuindo inclusive papel na elevação de certas produções a uma posição canônica. Quando investigamos academicamente 
essas encenações, é preciso admitir que a filmagem apresenta uma grande vantagem analítica, permitindo a elaboração de críticas menos impressionistas, que podem inclusive ser confrontadas posteriormente, além de facilitar o acesso à montagem - seja décadas depois, seja por seus contemporâneos geograficamente afastados ${ }^{2}$. As gravações audiovisuais de ópera atingem um público maior do que o dos frequentadores habituais dos teatros; três anos após o registro do ciclo do Anel do Nibelungo de Chéreau/Boulez, já estimava-se que a montagem, transmitida por televisão, fora vista por número maior de espectadores do que a soma daqueles que assistiram ao ciclo nas diversas produções teatrais ao redor do mundo desde 1876 (Senici, 2010). Desse modo, tais gravações tornam-se potencialmente a primeira forma com que considerável parte da sociedade trava contacto com a obra de Wagner e outros compositores, e possivelmente também a única em localidades desprovidas de teatros de ópera ou cujas temporadas contam com um número pequeno de producções e récitas - caso dos palcos líricos brasileiros.

Neste artigo, abordamos as limitações da gravação audiovisual para o registro de encenações operísticas de teatro de diretor, assim como recursos de linguagem de montagem fílmica que permitem reconstruir em texto audiovisual essas produções, com soluções por vezes distintas daquelas adotadas em palco. Interessa-nos, sobretudo, problematizar a equivalência que por vezes se estabelece entre uma encenação e sua gravação - especialmente no contexto contemporâneo de produções que realizam alterações temporada a temporada, quando não de uma récita para outra, e que se caracterizam pelo caráter único de cada performance individual, sempre repleta de eventos singulares, com relativa autonomia em relação ao plano geral de direção (Fischer-Lichte, 2004).

Para isso, discutimos problemas e soluções da direção de vídeo em gravações audiovisuais de encenações de Der Ring des Nibelungen [O Anel do Nibelungo], de Richard Wagner (1813-1883), ciclo de quatro óperas do qual Die Walküre3 é a segunda, junto a Das Rheingold [O Ouro do Reno], Siegfried e Götterdämmerung [Crepúsculo dos Deuses] - a tetralogia, uma alegoria política articulada a partir de material mitológico germânico e escandinavo, possui papel especial no desenvolvimento do teatro de diretor e na consolidação de sua prática, servindo de substrato para encenadores discutirem luta de classes, ecologia, opressão de gênero, ou mesmo para desafiar a própria noção de articulação de idéias no palco.

O corpus é constituído principalmente dos registros audiovisuais das seguintes produções:

- Festival de Bayreuth, 19804. Direção cênica de Patrice Chéreau e direção musical de Pierre Boulez.

- Ópera Metropolitana de Nova York, 1990. Direção cênica de Otto Schenk e direção musical de James Levine.

\footnotetext{
${ }^{2}$ Nesse sentido, a exibição das filmagens em salas de cinema e redes de televisão e a disponibilização em vídeo doméstico (VHS, Laserdisc, DVD e, mais recentemente, BluRay) ou serviços de streaming via internet tem sido bastante positiva, ao oferecer ao público à margem dos grandes centros culturais a possibilidade de assistir a um número considerável de produções.

${ }^{3} \mathrm{~A}$ referências às óperas serão feitas pelos títulos em alemão. No caso da tetralogia como conjunto também utilizamos como sinônimo, em português, "o Anel" e a expressão "ciclo do Anel" [Ring-Zyklus, Ring cycle], como é também conhecida.

${ }_{4}^{4} \mathrm{O}$ ano indicado é o da realização da gravação, não o da estreia das montagens.
} 
- Festival de Bayreuth, 1991-1992. Direção cênica de Harry Kupfer e direção musical de Daniel Barenboim.

- Ópera Estadual de Stuttgart, 2002-2003. Direção cênica de Joachim Schlömer (Das Rheingold), Christoph Nel (Die Walküre), Jossi Wieler e Sergio Morabito (Siegfried), Peter Konwitschny (Götterdämmerung), direção musical de Lothar Zagrosek e supervisão geral de Klaus Zehelein.

- Ópera Real Dinamarquesa (Kopenhagen), 2006. Direção cênica de Kasper Bech Holten e direção musical de Michael Schønwandt.

- Ópera Metropolitana de Nova York, 2010-2012. Direção cênica de Robert LePage e direção musical de James Levine e Fabio Luisi.

Além disso, mencionaremos aspectos do ciclo do Anel dirigido por Andreas Kriegenburg na Ópera Estadual Bávara em Munique (2013) e da ópera wagneriana Die Meistersinger von Nürnberg [Os Mestres-Cantores de Nuremberg] dirigida por Katharina Wagner no Festival de Bayreuth (2008)5.

\section{A ARQueOlogia das ENCENAÇões}

Um dos aspetos mais frustrantes de se pesquisar encenações operísticas é o caráter fragmentário das diversas outras formas de registro de produções do passado - fotografias, livros de produções, folhetos programáticos, resenhas em jornais e periódicos, historiografias de encenações. Talvez a inconformidade em relação à impossibilidade de recuperar a totalidade dessas produções seja um impulso completista também sintomático de nosso tempo, era do superarquivamento e superdocumentação - cuja cobertura se estende dos bastidores de obras literárias, musicais e cinematográficas a eventos pessoais supérfluos.

A consulta a esse material implica na tarefa arqueológica ${ }^{6}$ de reconstrução das produções a partir do cruzamento e confronto do conteúdo desses fragmentos, em geral bastante limitado aos aspetos visuais das produções, embora por vezes enriquecidos pela disponibilidade de material relacionado à sua conceção artística - ensaios ou entrevistas com a equipe criativa, esboços de cenário e figurino (quando devidamente acompanhados de informação contextual) e, em raros casos, documentos brutos da preparação crítica de uma produção ${ }^{7}$. Esse conteúdo está por vezes disponível também nos folhetos programáticos - que ganham dimensões de livro em companhias de grande porte como o Festival de Bayreuth, Festival de Salzburg e a Ópera Estadual Bávara -, embora o mais comum seja a reunião de críticas sobre a partitura ou o libretto, contexto social de conceção da ópera ou mesmo do material que lhe serviu de fonte ${ }^{8}$.

\footnotetext{
${ }^{5} \mathrm{~A}$ notação de referência às montagens será composta pelo sobrenome do director cênico e director musical. A gravação da tetralogia no Festival de Bayreuth em 1980, com direção cênica de Patrice Chéreau e direção musical de Pierre Boulez é mencionada, desse modo, como ciclo Chéreau/Boulez. No caso da produção de Stuttgart, em que diferentes directores trabalharam com cada parte do Anel em separado, optamos por indicar o nome do idealizador e director geral Klaus Zehelein, que responde academicamente pela produção.

${ }^{6}$ Lançamos mão do termo de modo a comparar a tarefa de reconstituição de uma produção de ópera ocorrida há anos ou décadas à investigação arqueológica, na qual se busca reunir resquícios de povos do passado de modo a se compreender sua cultura, seu modo de vida.

7 Uma importante coleção de documentos relacionados à produção do Anel nos anos 1970 está reunida em Mack (1978).

${ }^{8}$ No caso do Festival de Bayreuth, os mais relevantes ensaios relacionados às producções do Anel desde a fase Neu Bayreuth, iniciada em 1951, até o ciclo Chéreau/Boulez de 1976 foram reunidos em volume único (Barth, 1980).
} 
Os livros oficiais das produções, de um modo geral, reúnem um amplo número de fotografias e desse modo registram apenas a "pele" das montagens; poucos são os que de fato trazem material crítico ou relacionado aos bastidores e intenções da equipe criativa. As valiosas exceções são os livros das três produções do Festival de Bayreuth entre 1976 e 1992 - Chéreau/Boulez (1976-1980) (de Nussac, 1970), Hall/Solti (1983-1986) (Fay, 1985) e Kupfer/Barenboim (1988-1992) (Lewin, 1991) - e dois livros de natureza acadêmica produzidos em comemoração ao ciclo Zehelein/Zagrosek (Stuttgart) (Klein, 2001) e Nemirova/Weigle (Frankfurt) (Loebe \& Abels, 2013). O livro do ciclo Hall/Solti possui um caráter único por ter natureza jornalística, registrando em terceira pessoa o processo criativo da produção, em especial as dificuldades por conta dos choques culturais e metodológicos entre a equipe e o diretor do festival, Wolfgang Wagner, que contribuíram em parte para o fracasso do ciclo, junto a más escolhas no elenco e à mudança nas expectativas do público e da crítica após o choque inicial com as produções de realismo social dos anos 1970. O mau desempenho da produção levou Georg Solti a abandoná-la logo após o encerramento do primeiro festival, sendo substituído por Peter Schneider.

Há ainda livros dedicados à história e crítica da produção de diretores específicos - Wieland e Wolfgang Wagner, Götz Friedrich, Joachim Herz, Harry Kupfer, Peter Konwitschny, Klaus Zehelein, etc. - e historiografias de produções do Festival de Bayreuth (Olivier, 2007; Spotts, 1996, entre outros), das encenações dos dramas wagnerianos em geral (Carnegy, 2006; Bauer, 1983, entre outros) ou do Anel em específico (Eckert, 2001; Pargner, 2013, entre outros). Porém, todo esse material padece do mesmo tipo de problema: o foco no figurino e no cenário, com superficiais e esparsas menções às ações realizadas pelos atores - talvez inevitável, dada a necessidade de se lidar com um considerável número de produções em um espaço exíguo e à concentração da maior parte dessas obras (à exceção dos livros de Eckert e Pargner) sobre produções anteriores aos anos 1970. Isso é problemático porque o centro nervoso do teatro de diretor, em todas as suas abordagens, é justamente o gesto, que carrega em si maior profundidade na caracterização dos personagens e nos vínculos com o libretto e a música - seja em termos interpretativos ou de desafio e despeito em relação a eles. A gravação, por sua vez, permite revisitá-los de forma mais completa - embora apresente suas limitações.

Há diversas implicações no uso de registros audiovisuais não apenas como instrumento de pesquisa de produções operísticas, mas também de fruição - acreditamos que, para além das perdas, o saldo final é positivo. A primeira delas decorre da própria natureza da gravação: aquilo que é por natureza fugaz, conservado na memória dos espectadores e de outra maneira destruído pelo tempo, agora é preservado em uma memória artificial que pode ser consultada por quem não testemunha o evento. Esse é um ponto problemático em relação aos críticos que advogam em prol da autonomia do elemento performático, pois acaba por estabelecer um texto para uma dada produção, apresentá-lo como sua versão definitiva, uma recusa ao fato de que nenhuma récita será igual a outra (Risi, 2011) - tanto por alterações deliberadas como por diferenças sutis de execução, com maior e menor impacto, que se cristalizam no registro.

9 Citamos, como exemplo, o deslize de Robert Hale durante a despedida de Wotan a Brünnhilde no terceiro ato de Die Walküre do ciclo Lehnhoff/Sawallisch. Na cena, o pai das batalhas deve repetir as exclamações "Leb wohl!" [Adeus"] três 
A consulta a outras fontes disponíveis sobre as encenações por vezes permite identificar alterações que a equipe criativa realiza ao longo de diversas temporadas. Em um extra do DVD de Die Walküre no ciclo Holten/Schønwandt, há um diálogo de 36 minutos entre o diretor cênico Kasper Bech Holten e a rainha dinamarquesa Margrethe II no qual se revela, por exemplo, que um dos mais importantes gestos no primeiro ato da ópera - o momento em que Sieglinde (Gitta-Maria Sjöberg) retira a espada do tronco do freixo, em vez de Siegmund (Stig Andersen) - foi uma modificação implementada em 2006: na estréia da produção, em 2003, era o próprio Siegmund, como determinado por Wagner, quem realizava o ato. A mudança altera substancialmente o significado da cena e, se a gravação fosse realizada numa temporada anterior, a versão documentada em vídeo perderia um dos elementos que reforçam o argumento feminista da produção.

De maneira semelhante, o documentário Katharina Wagners Feuertaufe [A prova de fogo de Katharina Wagner], sobre os bastidores da produção do Festival de Bayreuth pela bisneta do compositor para Die Meistersinger von Nürnberg apresenta a primeira solução cênica para a apresentação de Beckmesser (Michael Volle) no concurso dos mestres-cantores. No libretto, o escrivão Sixtus Beckmesser encarna a incapacidade de criação autônoma - é um mestre-cantor que se limita a reproduzir recursos estilísticos catalogados e reconhecidos pelos seus pares - enquanto o protagonista Walther von Stolzing - seu rival na disputa de Eva Pogner, filha de outro dos mestres -, possui um impulso artístico bruto e, se ao final precisa compor uma meisterlied aproximadamente nos moldes esperados pela comissão julgadora - com a assistência de outro mestre-cantor, o sapateiro Hans Sachs -, ela ainda possui beleza e propriedades estéticas inovadoras, enquanto Beckmesser, desesperado pela vitória, recorre ao plágio - de uma versão nonsense do texto de Walther, que remete simultaneamente ao mito bíblico da criação do mundo e à Eva pela qual está apaixonado - e a uma estrutura composicional pobre, conservadora e desajeitada. Um dos aspetos mais marcantes da montagem de Katharina Wagner ${ }^{10}$, porém, é a elevação de Beckmesser de antagonista a herói moral da trama: ali Walther (Klaus Florian Vogt) é um performer que passa o primeiro e segundo atos realizando intervenções sobre o cenário com uma lata de tinta e pincel, porém ao longo do terceiro - quando recebe o auxílio de Hans Sachs (Franz Hawlata) -, curva-se às normas dos mestres-cantores e torna-se mais e mais conservador, a ponto de trocar seu estilo jovem de se vestir - uma jaqueta de couro, camisa pólo amarela e uma calça estampada com flores-de-lis - pela formalidade do terno e da gravata. Seu percurso no terceiro ato é interpretado como uma cooptação pelo comodismo e tradicionalismo do establishment; já Beckmesser - à revelia da caracterização fornecida pelo texto musical segue na direção oposta e, após ser atingido por respingos da tinta de Walther durante o tumulto no final do segundo ato, abandona seus trajes formais e toma para si o papel vanguardista, apresentando-se perante os mestres-cantores como um performer. $\mathrm{Na}$

vezes, mas Hale perde a primeira. A percepção do erro pelo público, por um lado, prejudica o envolvimento emotivo com a performance; por outro, de certo modo alivia o ar laboratorial e distante da gravação em relação à experiência presencial da ópera.

${ }^{10}$ Com cenários de Tilo Steffens, figurino de Michaela Barth e Tilo Steffens e direção musical de Sebastian Weigle. 
estréia da produção, em 2007, Beckmesser traz consigo um caixote de maçãs, de onde surge um homem nu, representação de Adão, segurando sua Eva, uma boneca inflável (Figura 1). Em 2008, ano em que foi realizada a filmagem lançada em DVD, Beckmesser arrasta consigo uma mesa coberta de terra escura e começa a moldá-la na forma de um homem também nu, que dela se ergue (Figura 2); Eva é uma mulher que entra em cena trajando um vestido vermelho e é despida por Beckmesser, enquanto seu Adão lança maçãs contra o coro - os espectadores do concurso -; já nua, Eva junta-se a ele.

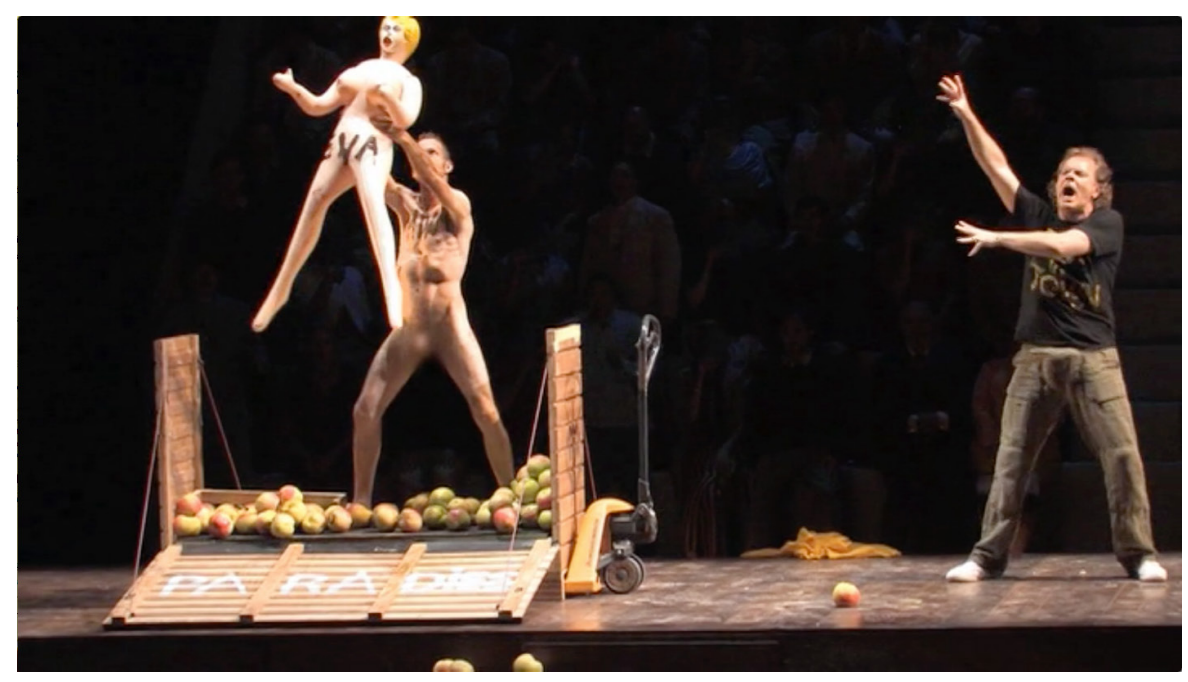

Figura 1: Em 2007, Beckmesser (Michael Volle) revela seus Adão e Eva num caixote de maçãs Fonte: Katharina Wagners Feuertafe - DVD

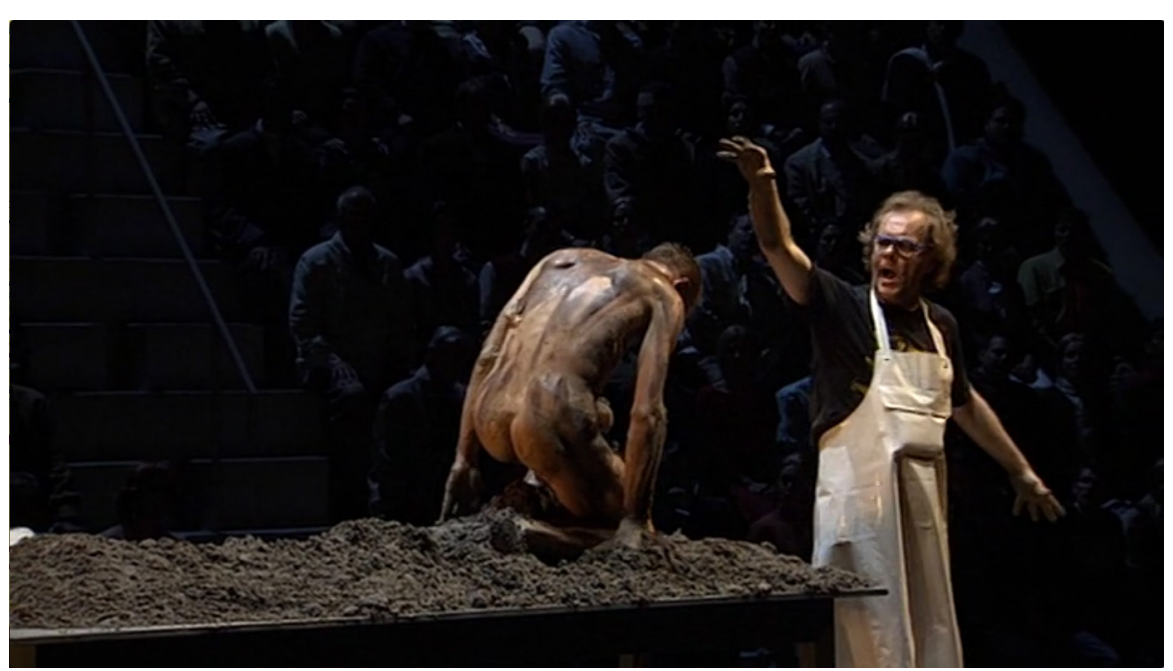

Figura 2: Em 2008, Beckmesser (Michael Volle) faz surgir um homem a partir da terra Fonte: Die Meistersinger von Nürnberg, Bayreuth 2008 - DVD

As duas soluções têm diversas implicações divergentes, tanto para a caracterização do papel de Beckmesser - que intervém de forma mais ativa durante a segunda versão da performance e assume um aspecto divino e literalmente criador ao fazer surgir um ser humano a partir da terra - quanto para os significados de sua apresentação - em 
2008, a mulher deixa de ser um brinquedo sexual carregado e manipulado pelo homem para ser um indivíduo autônomo, com suas próprias ações. Embora tenha havido aí uma mudança na proposta da direção cênica, não se pode desprezar que durante o Festival de Bayreuth de 2007 a cena com o caixote e a boneca inflável foi aquela a que o público assistiu, assim como o maior número de críticos - que sempre tendem a centrar suas atenções sobre a premiére daquele ano.

Assim, considerar apenas a récita lançada oficialmente em vídeo doméstico implicaria numa visão reduzida do trabalho realizado pela equipe criativa da montagem, que inclusive pode ter realizado novas alterações nos anos subsequentes - na verdade, é preciso cuidado até mesmo ao se considerar uma gravação como uma récita propriamente dita, visto que é comum compor o registro audiovisual a partir de várias tomadas, gravadas em datas distintas: nesses casos, o material exibido em vídeo nunca ocorreu enquanto récita integral. Há inclusive diferenças em composições de elenco que precisam ser levadas em consideração - durante os três primeiros anos do ciclo Chéreau/ Boulez em Bayreuth, por exemplo, Siegfried foi interpretado por René Kollo, substituído em 1979 por Manfred Jung, bastante inferior enquanto cantor, embora seja um ator mais expressivo.

\section{LIMITAÇÕES FÍSICAS E FÍLMICAS}

As insuficiências da filmagem em relação à experiência presencial, no entanto, não se limitam às variações entre uma e outra récita, à dimensão performática: a própria materialidade da ópera ao vivo é bastante distinta da gravação audiovisual, uma vez que a captura de imagens e a montagem fílmica agem como um novo nível de mediação entre o espectador e a produção e juntos constituem um quarto texto que delimita a apreciação do texto cênico e em vários aspetos constrói uma narrativa sobre ele. Os autores desse outro nível textual são as câmeras e o diretor de fotografia.

A câmera é um espectador ideal munido de binóculos especiais, que lhe permitem diversos graus de zoom, assim como vários ângulos de visão distintos, o que libera o acesso para detalhes por vezes indesejáveis quando existe uma expectativa de manutenção da narrativa operística como ilusão, como no caso das produções da Ópera Metropolitana de Nova lorque: na gravação do Rheingold do ciclo Schenck/Levine, vemos o Loge de Siegfried Jerusalem suando em bicas por conta da maquiagem, enquanto o Siegmund de Jonas Kaufmann cospe e baba em profusão na Walküre de LePage/Levine. Porém, o espectador da gravação não tem autonomia para decidir para onde irá dirigir seu olhar e focar sua atenção: as câmeras e a montagem fílmica decidem o que se vê na cena no lugar do espectador, que passa a ter um papel bem mais passivo.

Isso é bastante problemático especialmente nas produções posteriores aos anos 1990, quando se fortaleceu o paradigma pós-dramático, em que é comum haver cenas em que há uma multiplicidade de acontecimentos simultâneos, vários deles importantes: cito como exemplo o final do primeiro ato do Siegfried com direção cênica de Andreas Kriegenburg e regência de Kent Nagano, integrante do ciclo que estreou em 2012, 
quando Siegfried forja novamente Notung, a espada de seu pai que havia sido partida em duas por Wotan em Die Walküre, e o nibelungo Mime prepara uma bebida sonífera que tentará utilizar para assassinar Siegfried no ato seguinte. Na partitura, Wagner distingue bem os momentos em que um e outro recebe destaque, mas na produção de Kriegenburg essa hierarquia é quebrada e ambos estão bastante ativos o tempo todo - Siegfried constrói e opera um fole com a ajuda de alguns figurantes, enquanto outros servem de cobaia para testes de Mime com diferentes fórmulas de veneno e ainda outros agrupamentos de membros da figuração atuam de forma independente. Uma composição de cena dessa natureza será certamente castrada pelo direcionamento do olhar de um registro audiovisual, dada a impossibilidade de exibir satisfatoriamente todas as ações; uma gravação de arquivo de 2012 da Ópera Estadual Bávara" encontrou como solução o uso de um plano aberto que enquadrava todo o palco, porém essa é uma estratégia que em termos de fruição audiovisual não funciona bem: há uma grande diferença entre observar o palco presencialmente e um palco filmado de forma estática - no segundo caso, perde-se a noção de profundidade e mesmo o envolvimento com a ação, conforme os atores parecem minúsculos e perdem sua individualidade.

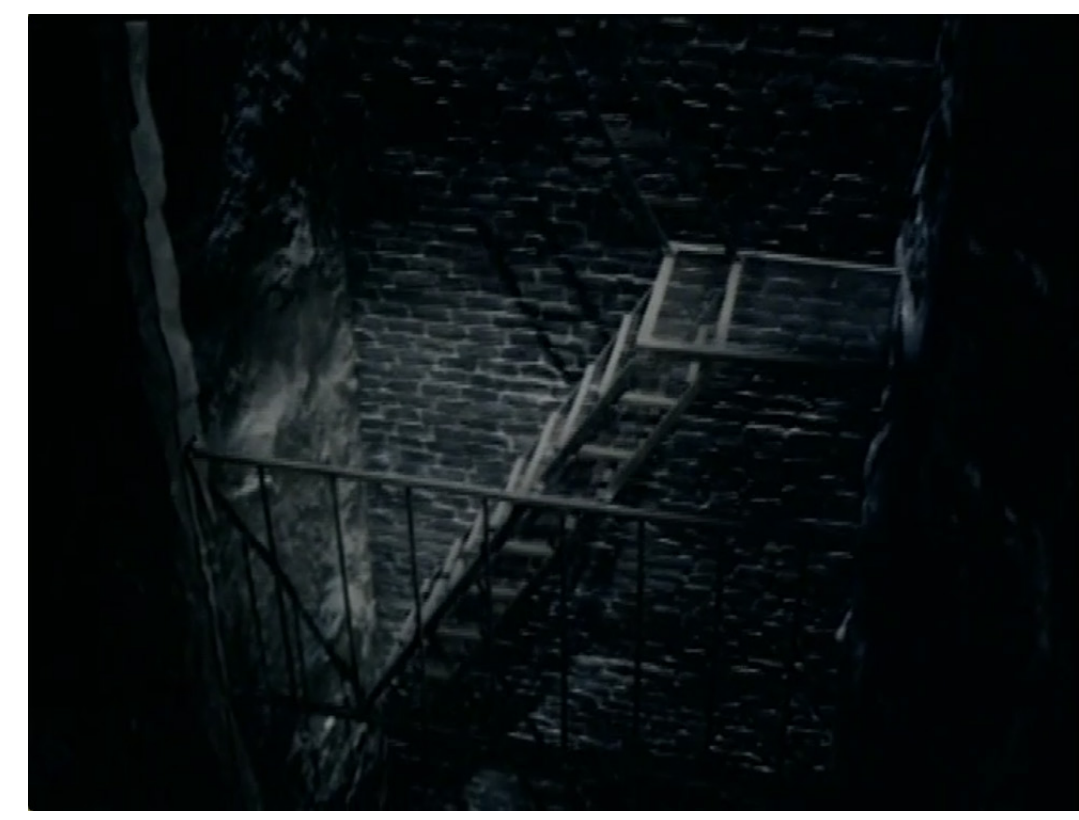

Figura 3: Passagem por um lance de escadas representa a descida de Wotan e Loge ao Nibelheim Fonte: Das Rheingold, Bayreuth 1980 - DVD

A estratégia que se tornou padrão na filmagem de ópera (Citron, 2000) envolve o uso de planos intermediários - como o americano - para registrar a narrativa cênica em seu andamento normal, closes e super closes para reforçar a expressão de emoções e o uso ocasional do plano geral apenas para contextualizar o espaço onde a ação como um todo se desenvolve - ou registrar ações que envolvem deslocamentos por toda a extensão

\footnotetext{
"Apresentada durante o seminário de três dias ministrado por Jürgen Schläder no Capriccio-Saal do Nationaltheater de Munique de acompanhamento das récitas do ciclo Kriegenburg/Nagano no festival de verão da Ópera Estadual Bávara em julho de 2013.
} 
do palco. A alternância de tomadas de planos distintos varia bastante de acordo com a gravação: no ciclo Chéreau/Boulez, por exemplo - quando ainda se desenvolviam estratégias de filmagem de récitas de ópera - há maior uso do plano geral do que nos posteriores; a pedido de Kupfer, a produção que realizou para o teatro de Bayreuth foi filmada sempre frontalmente, simulando os ângulos de visão que membros da platéia teriam; num gesto oposto, o diretor de fotografia do ciclo Holten/Schønwandt, Uffe Borgwardt, plantou câmeras no cenário - de qualidade mais baixa do que as câmeras de filmagem frontal -, que possibilitavam visualizar a ação por ângulos impossíveis ao público, e durante a montagem do filme optou por alternar com frequência o ponto de vista utilizado - o que por vezes se torna bastante incômodo, especialmente pela interrupção no registro de alguma ação para que se mostre outra que acontecia simultaneamente no palco.

Há também casos em que a montagem fílmica é utilizada para a inserção de imagens que não correspondem ao que estava visualmente disponível ao público durante a récita - isso ocorre principalmente durante passagens orquestrais, especialmente na abertura de atos ou em transições de cenas, em que a cortina permanece fechada, ou o palco está imerso na escuridão por muito tempo. Na gravação do ciclo Lenhoff/Sawallisch - assim como em Schenk/Levine - a transição é preenchida por uma animação que simula as águas do rio Reno - entre a primeira e segunda cenas de Das Rheingold - ou por fumaça em movimento, colorida por meio de iluminação: aparentemente, há um grande receio de que o espectador se entendie e o diretor de vídeo prefere preencher a tela com qualquer imagem, ainda que abstrata e desconectada do conteúdo da ópera. Já no ciclo Chéreau/Boulez a solução encontrada foi exibir animações que simulassem a troca de cenário nos bastidores - o que possibilita um novo tipo de olhar privilegiado ao espectador, dessa vez penetrando por detrás das cortinas de Bayreuth -, ou mesmo a descida de Wotan e Loge ao Nibelheim (Figura 3), representada por um lance de escadas, dessa vez integrando de fato a transição de cenas à narrativa da ópera ao acrescentar informação efetivamente relacionada à produção.

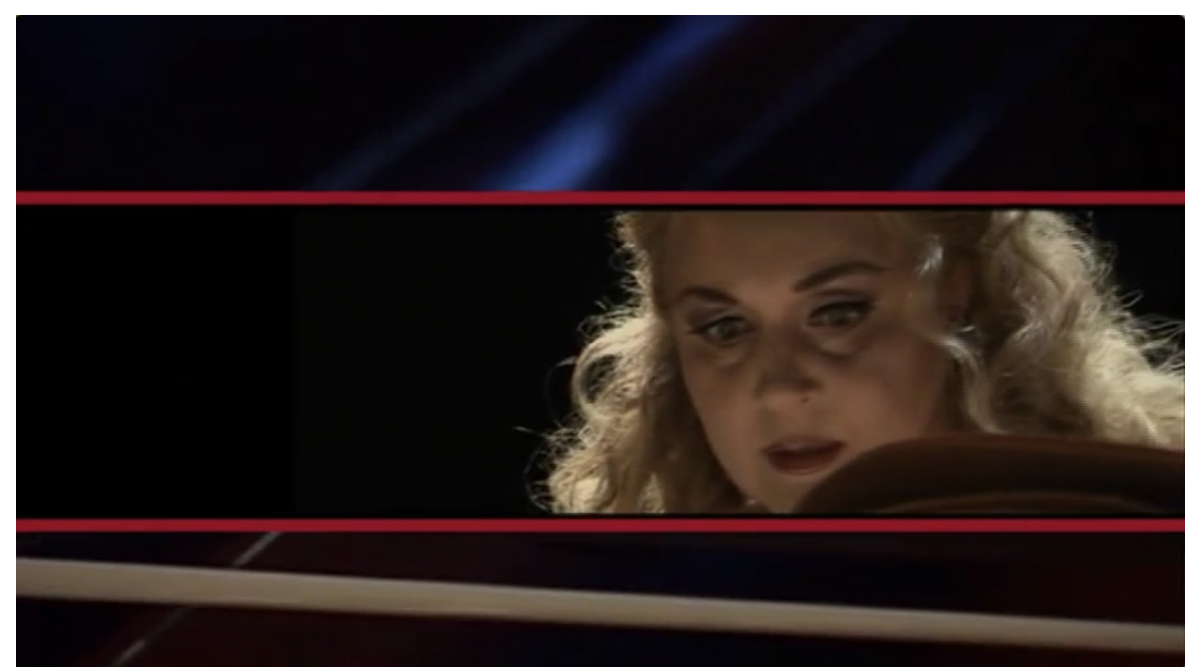

Figura 4: Nas transições entre cenas, Brünnhilde (Irene Théorin) consulta os arquivos da famíla Fonte: Das Rheingold, Kopenhagen 2006 - DVD 
A estratégia em Holten/Schønwandt é mista: por um lado, há também um esforço em contribuir para a narrativa ao se exibir tomadas em que Brünnhilde (Irene Théorin) vagueia por uma biblioteca para consultar os arquivos de Wotan (Figura 4) ou então reprises, em câmera lenta, de excertos de cenas - a moldura que se imprime à produção é de que todos os acontecimentos até o terceiro ato de Götterdämmerung são flashbacks da valquíria -; porém por vezes o que o vídeo exibe são tomadas da orquestra, recurso utilizado também nas filmagens de Zeheilen/Zagrosek e Pilavachi/Brogli-Sacher e, de um modo geral, bastante comum em gravações audiovisuais de ópera. Esse é um procedimento bastante discutível também, pois realiza um rompimento na continuidade textual da encenação - problemático especialmente em produções wagnerianas, se recordarmos o desejo do compositor de que o público se concentrasse exclusivamente na ação no palco, o que levou à criação de um fosso especial para o teatro que projetou em Bayreuth, no qual a orquestra está totalmente oculta' ${ }^{12}$.

A filmagem pode produzir ainda outros tipos de ruído em relação à encenação documentada. Um dos aspetos visuais mais chamativos do ciclo Kupfer/Barenboim foi o uso de lasers, especialmente para a representação do fogo que cerca a rocha onde Brünnhilde jaz adormecida em Die Walküre e Siegfried e do rio Reno em Das Rheingold e Götterdämmerung - neste caso, porém, foi necessário mudar a cor do laser de azul escuro para um verde fosforescente, pois a frequência da luz utilizada originalmente não aparecia como um feixe contínuo no vídeo (o efeito pretendido), mas com intermitências: a alteração, porém, está de acordo com a proposta da produção, ambientada em um futuro pós-apocalíptico, devastado por uma catástrofe nuclear ${ }^{13}$. O registro audiovisual também é canhestro na captação de projeções lançadas sobre o palco, muito comuns, nos últimos anos, para simular o fogo que reveste a rocha de Brünnhilde, e essenciais no ciclo LePage/Levine/Luisi, em que o cenário é todo formado a partir de projeções de imagens sobre um conjunto de placas de alumínio - em diversas tomadas em que há ângulos fechados, a projeção empalidece ou mesmo desaparece quando em contraste com a iluminação de palco, e tem seu efeito arruinado.

É preciso mencionar, contudo, momentos em que o uso de diversas câmeras e da montagem fílmica contribuem de forma bastante positiva na emulação do texto cênico in loco, em especial na primeira cena do Götterdämmerung de Holten/Schønwandt e durante o terceiro ato do Götterdämmerung do ciclo Konwitschny/Zagrosek. Em Kopenhagen, o vídeo se inicia com o fosso da orquestra e logo passa à parte central da primeira fila da platéia, que recebe iluminação directa mas não parece se incomodar com isso; uma mulher corpulenta de peruca ruiva (Susanne Resmark) chama a atenção de seu vizinho de assento para o fato e é gentilmente dispensada para que se concentrem na récita - então, ela canta: “Welch Licht leuchtet dort?” [Que luz é essa que brilha ali?]. A segunda norna (Hanne Fischer) surge algumas fileiras atrás (Figura 5), e a terceira (Anne Margrethe Dahl) nas coxias. A colocação de intérpretes em meio ao público - e ali as

\footnotetext{
${ }^{12}$ Mas evidentemente, ao tratarmos das produções em teatro de director, por bem ou por mal a intencionalidade autoral do compositor não figura mais entre as preocupações dos realizadores.

${ }^{13}$ O ciclo estreou em 1988, dois anos após a explosão do quarto reator da usina de energia nuclear de Chernobyl.
} 
nornas encarnam justamente habitués das casas de ópera, críticas de jornal e membros de sociedades wagnerianas - é o tipo de solução de difícil reconstrução em filme - especialmente quando, como no caso, as atrizes estão fisicamente distantes -, mas a proposta de montagem de Uffe Borgwardt, com câmeras estrategicamente posicionadas e rápida alternância entre pontos de vista, neste caso contribuiu bastante para recriar a cena com fluidez.

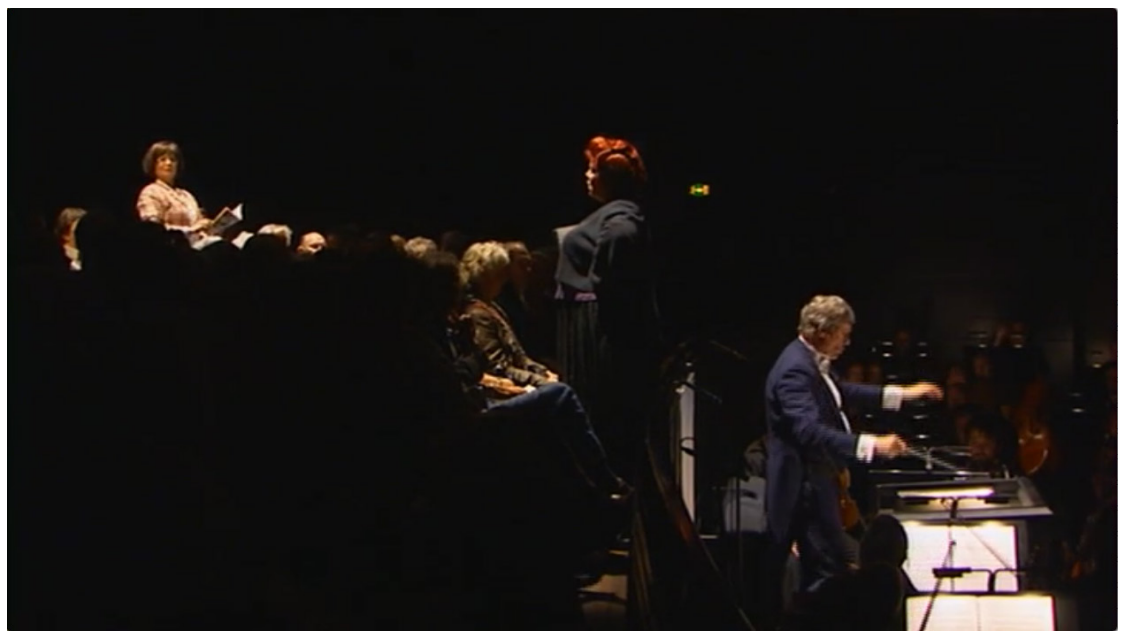

Figura 5: O diálogo das nornas é realizado em meio ao público da Ópera Real Dinamarquesa Fonte: Götterdämmerung, Kopenhagen 2006 - DVD

Um uso bastante inteligente de planos e da montagem foi também necessário no caso da produção de Peter Konwitschny para Götterdämmerung em Stuttgart, durante o início da segunda cena do terceiro ato - quando Siegfried (Albert Bonnema), sem conseguir achar sua trompa de caça, pede a um trompista da orquestra que toque por ele, em resposta aos chamados do grupo de Gunther e Hagen - e durante toda a terceira cena a partir da entrada de Brünnhilde (Luana DeVol), quando as luzes do teatro se acendem e os personagens e figurantes no palco tomam consciência de que são atores em uma récita de ópera. A estratégia do diretor de vídeo Hans Hulscher consistiu na alternância de tomadas dos atores no palco com outras que mostrassem a platéia, o que é especialmente eficaz no momento em que as luzes se acendem e os atores a observam atônitos - a montagem fílmica permite recriar, narrativamente, a interação entre intérpretes e público - e no uso de planos bastante abertos que mostrassem simultaneamente o palco e as primeiras fileiras da platéia, no intuito de evitar um retorno do espectador à imersão na encenação, o que implicaria na perda do efeito de quebra da quarta parede.

Ainda assim, o enquadramento e a montagem dessa sequência de tomadas funcionam apenas como tentativa de compensação por uma experiência que se perde, uma vez que o efeito obtido presencialmente - a surpresa e o incômodo na visão por estar numa platéia subitamente iluminada, receber diretamente os olhares intrigados dos atores, da mesma forma como ser encarado pelo proletariado que sobrevive à catástrofe no final do ciclo Chéreau/Boulez - é irrecuperável na filmagem. 


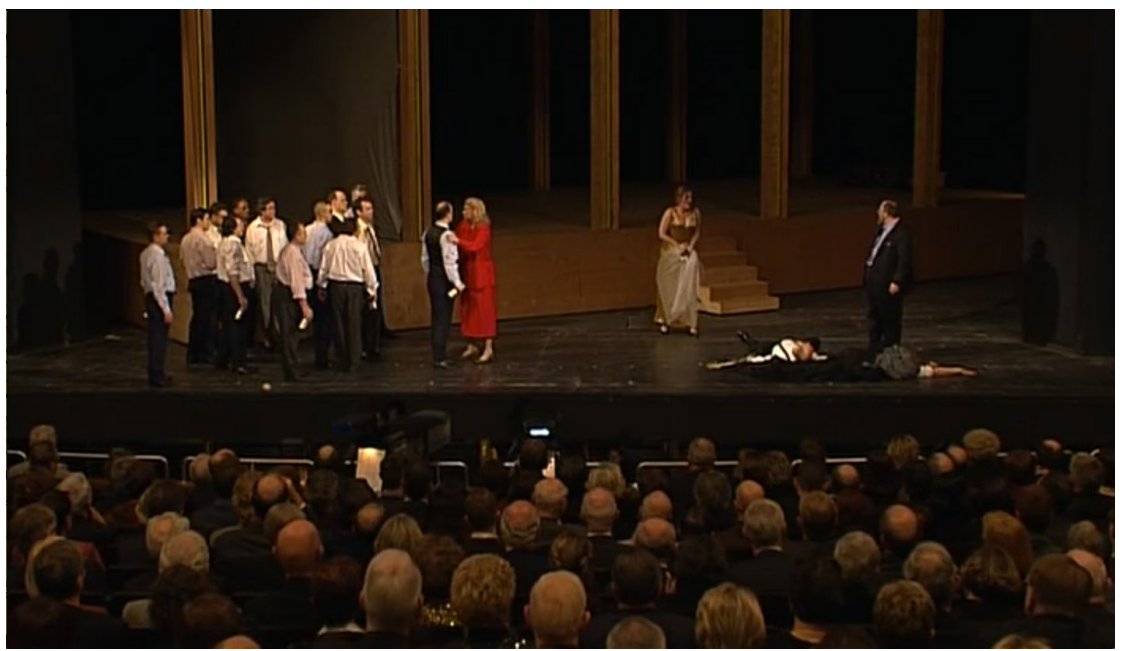

Figura 6: O uso do plano geral tenta recriar em vídeo a quebra da quarta parede na produção de Konwitschny Fonte: Götterdämmerung, Stuttgart 2003 - DVD

\section{CONCLUSÕES: O MUNDO ENGARRAFADO}

Vamos ao último aspeto de que somos privados ao assistir a uma gravação: a experiência comunitária, talvez uma forte razão para a cultura da ópera se manter tão viva na Alemanha e em grandes centros mundiais. Ler o libretto, a partitura ou o folheto programático antes das récitas e durante os intervalos - aproveitá-los para finalmente sentar após ter ficado por mais de uma hora assistindo à produção em pé -, trocar opiniões sobre a apresentação com amigos ou desconhecidos, caminhar pelo foyer ou pelo jardim (onde também se faz piqueniques, no caso de Bayreuth), observar os bustos de compositores e diretores artísticos da casa, ir à loja do teatro ou ao refeitório, receber pelos alto-falantes da casa, como ocorrido em julho de 2013 , a notícia de que Klaus Florian Vogt, que interpretaria o papel-título em Lohengrin, está doente e será substituído por Jonas Kaufmann, seguida de ruidosos e entusiasmados aplausos - tudo isso integra a experiência do espectáculo.

Werner Herzog encontrou uma expressão formidável para definir a arte da produção operística: "a transformação do mundo em música" [Die Verwandlung der Welt in Musik], que dá nome a seu documentário sobre os bastidores do Festival de Bayreuth em 1993 - partircularmente verdadeira quando se trata dos dramas wagnerianos, em que há uma ânsia por captar e expressar diversas dimensões da experiência do mundo - sensoriais, emotivas, éticas, políticas. Nas gravações dessas produções, porém, tudo a que temos acesso é um mundo engarrafado, enclausurado pelo ecrã, uma representação leve ou severamente distorcida pela superfície de mediação, como vimos no decorrer deste artigo.

Num teatro de ópera tradicional temos uma série de possibilidades de assentos de preço variável de acordo com o conforto, proximidade e qualidade da visibilidade do palco oferecidos, indo de $€ 7.50$ para se assistir à recita em pé na galeria, não raro com visão parcial ou mesmo visão alguma do palco, a € 200 para os melhores assentos na platéia ${ }^{14}$.

\footnotetext{
${ }^{14}$ Uso aqui, como exemplo, valores atuais do Nationaltheater, em Munique.
} 
Cada posição oferece, certamente, uma experiência diferente da mesma apresentação: é possível, por exemplo, estar instalado numa coxia e ter parte do palco fora do campo de visão, o que significa que passaremos alguns minutos torcendo mentalmente para que os atores se desloquem ao menos para a parte central e frontal do palco e, apesar dessa desvantagem, poder observar certos elementos do cenário - e possivelmente isso se estenderá a certas ações - que ficam ocultos aos espectadores que estão de frente para o palco. A situação é um pouco distinta em casas com estrutura de anfiteatro, que oferecem condições de maior igualdade entre os espectadores, com variação na proximidade do palco e alguns poucos assentos com visão parcial ou nula - caso da Festspielhaus de Bayreuth, inovadora em arquitetura de teatros de ópera, e o Prinzregententheater de Munique (fortemente inspirado no templo wagneriano).

No caso da gravação, a limitação física do assento é substituída por um olhar privilegiado que está mais próximo do palco - e, por extensão, do cenário e dos atores - do que seria possível a qualquer membro do público. Há, inegavelmente, um distanciamento emotivo em relação à produção - produzido inclusive pela própria natureza autiaurática do ecrã (Mendonça, 2010) -, especialmente nesses momentos em que o ambiente do teatro integra de algum modo o texto cênico: a suspensão de descrença é rompida e o espectador é lembrado de que não está assistindo a uma récita de ópera, mas a um registro de uma récita, cujo ponto de vista é mediado por câmeras e a narrativa reconstruída a partir da montagem fílmica. O mesmo ocorre em relação aos curtain calls, que perdem muito de seu sentido em registros audiovisuais, uma vez que o espectador não pode participar ativamente, com aplausos ou vaias - embora haja quem o faça em transmissões cinematográficas ao vivo de récitas da Ópera Metropolitana de Nova lorque, em seu programa MetLiveHD -, ou mesmo se ressignificam, oferecendo uma experiência de estudo de receção da récita e dos intérpretes.

Certamente o uso de uma gravação como equivalente à totalidade da produção é ingênuo e enganoso. Contudo, é também problemático considerar a apresentação a que se assiste ao vivo, presencialmente, como a única maneira possível de compreender a encenação - afinal, dada a inviabilidade de se acompanhar todas as récitas, inevitavelmente um crítico terá de tratar de apenas uma, ou de um número reduzido delas, e ao realizar sua análise estará também limitado a essa amostra - assim como, impossibilitado de repetir a experiência de uma récita, escreverá centrado sobre aquilo que conseguiu captar durante a apresentação; tudo o que escapar à sua atenção e memória estará perdido e irrecuperável. A gravação audiovisual ainda é o mais satisfatório instrumento de que dispomos na empreitada arqueológica de recuperação de realizações artísticas do passado.

\section{FinANCIAMENTOS}

Pesquisa financiada com bolsa de doutorado do Conselho Nacional de Desenvolvimento Científico e Tecnológico (CNPq, Brasil, processo $n^{\circ} 141241 / 2011-0$ ) e bolsa de doutorado sanduíche da Coordenação de Aperfeiçoamento de Pessoal de Nível Superior (CAPES, Brasil, processo nº 18298-12-5). 


\section{REFERÊNCIAS BIBLIOGRÁFICAS}

Barth, H. (Ed.) (1980). Bayreuther dramaturgie: Der Ring des Nibelungen. Stuttgart/Zürich: Belser.

Bauer, O. G. (1983). Richard Wagner: The stage designs and productions from the Premières to the present. Nova lorque: Rizzoli.

Carnegy, P. (2006). Wagner and the art of the theatre. New Haven: Yale University Press.

Citron, M. J. (2000). Opera on screen. New Haven: Yale University Press.

Eckert, N. (1995). Von der oper zum musiktheater. Berlim: Henschel.

Eckert, N. (2001). Der Ring des Nibelungen und seine Inszenierungen von 1876 bis 2001. Hamburgo: Europäische Verlagsanstalt.

Ely, N. (1984). Und so haben wir das regietheater in der oper. In N. Ely \& S. Jaeger (Eds.), Regie Heute: Musiktheater in Unserer Zeit (pp. 225-237). Berlim: Quadriga.

Fay, S. (1985). The Ring: Anatomy of an opera. Dover: Longwood Press.

Fischer-Lichte, E. (2004). Ästhetik des performativen. Frankfurt: Suhrkamp.

Garaventa, A. (2006). Regietheater in der oper. Munique: Martin Meiden Bauer.

Herz, J. \& Kobán, I. (Eds.) (1989). Theater-Kunst des erfüllten augenblicks. Berlim: Henschel.

Joyce, J. (2000). Finnegans wake. Londres: Penguin.

Klein, R (Ed.) (2001). Narben des gesamtkunstwerks: Wagners Ring des Nibelungen. Munique: Wilhelm Fink.

Lehmann, H. T. (1999). Postdramatisches theater. Frankfurt: Verlag der Autoren.

Lewin, M. (Ed.) (1991). Der Ring Bayreuth 1988-1992. Hamburgo: Europäische Verlagsanstalt.

Loebe, B. \& Abels, N. (Eds.) (2013). Schafft neues!... Richard Wagner in Frankfurt. Frankfurt: axel dielmann-verlag.

Mack, D. (Ed.) (1978). Theaterarbeit an Wagners Ring. Munique: Piper.

Maffesoli, M. (2011). Pós-modernidade. Comunicação e Sociedade, 18, 21-25.

Mendonça, P. F. X. (2010). Objectos, poder e oculto - Sobre a experiência do ecrã. Comunicação e Sociedade, $17,51-66$.

Nussac, S. (Ed.) (1980). Der “Ring” Bayreuth 1976-1980. Berlim: Kristrall-Verlag.

Olivier, P. (2007). Der Ring des Nibelungen in Bayreuth von den Anfängen bis heute. Mainz: Schott.

Pargner, B. (Ed.) (2013). Von der welt anfang und ende: "Der Ring des Nibelungen in München". Leipzig: Henschel.

Parker, R. \& Abbate, C. (2012). A history of opera: The last four hundred years. Londres: Allen Lane.

Passos, M. (2015). Eram os deuses magnatas? A reconstrução textual de Der Ring des Nibelungen pelo teatro de diretor. Tese de doutorado, Universidade Estadual de Campinas, Brasil. Retirado de http:// repositorio.unicamp.br/handle/REPOSIP/269953 
Risi, C. (2011). Opera in performance: in search of new analytical approaches. The Opera Quarterly, 27, $283-295$

Senici, E. (2010). Porn style? Space and time in live opera videos. The Opera Quarterly, 26, 63-80.

Spotts, F. (1996). Bayreuth: A history of the Wagner Festival. New Haven: Yale University Press.

\section{NOTA BIOGRÁFICA}

Mateus Yuri Passos é pesquisador pós-doutorado no Programa de Pós-Graduação em Comunicação da Faculdade Cásper Líbero (São Paulo, Brasil) e é editor adjunto da Revista Comunicação Midiática.

Doutor em Teoria e História Literária (Unicamp), com período sanduíche na Ludwig-Maximilians-Universität München.

E-mail:mateus.passos@gmail.com

Faculdade Cásper Líbero

Avenida Paulista, 900, 01310-940 São Paulo-SP, Brasil

* Submetido: 01-10-2016

* Aceite: 23-01-2017 